\title{
Clear cell carcinoma of the ovary: Potential pathogenic mechanisms (Review)
}

\author{
HIROTAKA KAJIHARA, YOSHIHIKO YAMADA, SEIJI KANAYAMA, NAOTO FURUKAWA, \\ TAKETOSHI NOGUCHI, SHOJI HARUTA, SHOZO YOSHIDA, TOSHIYUKI SADO, \\ HIDEKAZU OI and HIROSHI KOBAYASHI
}

Department of Obstetrics and Gynecology, Nara Medical University, Nara, Japan

Received December 30, 2009; Accepted February 25, 2010

DOI: 10.3892/or_00000750

\begin{abstract}
Epithelial ovarian cancer (EOC) is the most common cause of gynecological cancer-related mortality. Clear cell EOC (cEOC) has a number of clinical features distinguishing it from other EOC because of frequent concurrence of endometriosis and highly chemoresistant nature resulting in a poor prognosis. Recent biochemical studies based on genomewide expression analysis technology have noted specific expression of a transcription factor, hepatocyte nuclear factor-1ß (HNF-1ß), in cEOC and genetic alteration may be involved in oxidative stress. We describe the HNF-1ßdependent pathophysiology of cEOC and discuss its role in oxidative stress-induced carcinogenesis. A systematic search was performed in the electronic databases PubMed and ScienceDirect up to July 2009, combining the keywords, genome-wide, microarray, epithelial ovarian cancer, clear cell carcinoma, oxidative stress, and detoxification, with specific expression profiles of genes. The catalog of cEOC-specificity might be a manifestation of six essential alterations in cell physiology: oxidative stress and detoxification, proteases, signal transduction, adhesion, transcription, and metabolism. Among 54 genes highly upregulated in cEOC, 47 genes $(87.0 \%)$ were associated with the redox-related genes. Several important cEOC-related genes overlap with those known to be regulated by HNF-1ß. Twenty-two $(40.7 \%)$ of the 54 genes predominantly identified in cEOC were involved in downstream targets of HNF-1ß. The HNF-1ß-dependent pathway might provide new insights into regulation of glycogen synthesis, detoxification and resistance to anticancer agents. This review summarizes recent advances in the understanding of oxidative stress and antioxidant mechanisms in pathogenesis of cEOC. A redox-sensitive subset of cEOC genes linked to oxidative and detoxification
\end{abstract}

Correspondence to: Dr Hiroshi Kobayashi, Department of Obstetrics and Gynecology, Nara Medical University, 840 Shijo-cho, Kashihara 634-8522, Japan

E-mail: hirokoba@naramed-u.ac.jp

Key words: clear cell carcinoma, detoxification, epithelial ovarian cancer, oxidative stress, pathophysiology pathways was identified and associated with HNF-1ß-specific downstream targets.

\section{Contents}

1. Introduction

2. Specific expression of stress-related genes in $\mathrm{cEOC}$

3. Pro-oxidative and antioxidative balance in cEOC

4. Genes involved in oxidative stress and detoxification in cEOC

5. Specific expression of HNF-1ß and its downstream targets in $\mathrm{cEOC}$

6. Conclusions

\section{Introduction}

Epithelial ovarian cancer (EOC) remains the most lethal form of gynecologic cancers worldwide. The four morphologically defined EOC subtypes, serous, endometrioid, mucinous, and clear cell carcinomas, encompass the vast majority of EOC. They have been generally believed to originate from ovarian surface epithelium, cortical inclusion cyst, peritoneal mesothelium, or the fallopian tubal fimbria (1). Recent progress in pathophysiology, biochemistry and molecular biology has revealed many genetic and epigenetic alterations as well as several genetic networks and signaling pathways that are considered to be involved in the development and progression of EOC (2). A number of genetic alterations are frequently encountered during EOC tumorigenesis, including oncogenic activation of KRAS (v-Ki-ras2 Kirsten rat sarcoma viral oncogene homolog), BRAF (v-raf murine sarcoma viral oncogene homolog B1), PI3K (phosphatidylinositol 3-kinase)/Akt (v-akt murine thymoma viral oncogene homolog) and Wnt (winglesstype MMTV integration site family)/ß-catenin/Tcf pathways, and silencing mutations of TP53 (tumor protein p53), RB (retinoblastoma) and PTEN (phosphatase and tensin homolog) $(2,3)$.

Kurman et al has recently proposed a model of ovarian carcinogenesis (2). Similar to uterine endometrial carcinoma, this model divides EOC into two groups designated type I and type II. Type I tumors are slow growing, low-grade EOC and show stepwise progression as an adenoma-carcinoma sequences. They are often characterized by mutations in 
KRAS, BRAF, PTEN and B-catenin genes (3). For example, low-grade serous-type EOC (sEOC) carry mutations frequently in KRAS or BRAF genes. Endometrioid-type EOC (eEOC) are predominantly related to PTEN mutation and concomitant activation of the PI3K/Akt (4) and sometimes Wnt/ß-catenin/ Tcf pathways (4). KRAS mutation or single nucleotide polymorphism (SNP) in KRAS and BRAF are relatively common in the mucinous-type EOC (mEOC) $(5,6)$. There is one study showing that clear cell-type EOC (cEOC) may have an activating mutation of PIK3CA (phosphoinositide-3-kinase, catalytic, $\alpha$-polypeptide) (7). However, the molecular mechanisms that underlie the pathogenesis of cEOC remain largely unknown. In contrast, type II tumors are rapidly growing and do not have recognizable precursor lesions such as adenomas. High-grade sEOC showed mutations of $\mathrm{p} 53$ and BRCA1/2 and a high level of genetic instability (3). Type II tumors account for most EOC.

The incidence of cEOC has been steadily increasing in Japan. They comprise $>20 \%$ of all EOC (8). cEOC has a number of clinical features distinguishing it from other EOC because of its complication of thromboembolism and frequent concurrence of endometriosis, and highly chemoresistant nature resulting in an extremely poor prognosis. cEOC involves various putative precursor lesions including atypical endometriosis or borderline adenofibroma $(9,10)$. Thus, it is likely that cEOC belong to type I tumors. Successful animal models may substantiate the role of genetic alterations in human EOC. The majority of the models result in EOC with histological similarity to sEOC and eEOC. However, animal models designed for other types of EOC are lacking (11).

\section{Specific expression of stress-related genes in cEOC}

Recent developments in the molecular biology of cEOC support the hypothesis that $\mathrm{CEOC}$ has a distinct gene expression profile relative to other EOC histotypes (12). Many genes preferentially overexpressed in cEOC have been identified so far $(13)$. In the reviews reported previously $(8,12)$, they summarized the specific gene expression profiles and the current knowledge on the new therapeutic targets and treatment strategies for cEOC. There are 54 genes highly upregulated in cEOC (Table I).

The catalog of cEOC-specificity is a manifestation of six essential alterations in cell physiology: oxidative stress and detoxification, proteases, signal transduction, adhesion, transcription, and metabolism $(8,12)$. The expression of the genes involved in detoxification $(n=12)$, proteases $(n=9)$, cell signaling $(n=7)$, adhesion $(n=5)$, transcription $(n=4)$, metabolism $(n=4)$, cell cycle $(n=3)$, matrix $(n=3)$, and others $(n=7)$ was specifically increased in the cEOC carcinogenesis. The biological function of these genes is considered to be associated with glycogen synthesis, chemoresistance, and anti-apoptosis. Among 54 genes highly upregulated in cEOC, 47 genes $(87.0 \%)$ were associated with the redox-related genes $(8,12,13)$ (Table I and Fig. 1). We found that the vast majority of genes that increased in cEOC overlap the oxidative stress-related genes. These gene profiles might distinguish between cancers in a validation series of cEOC versus other histological types. Recently, Mandai et al has reported that the classification of the genes represents those

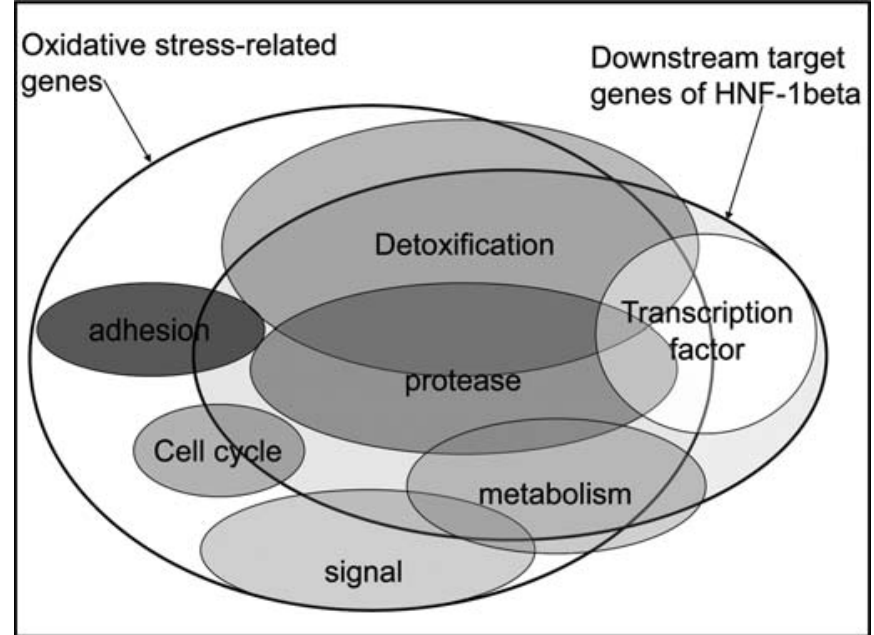

Figure 1 . Genes highly expressed in clear cell carcinoma of the ovary. The expression of the genes involved in detoxification, proteases, cell signaling, adhesion, transcription, metabolism, cell cycle, matrix, and others was specifically increased in the cEOC carcinogenesis. Among 54 genes highly upregulated in cEOC, 47 genes $(87.0 \%)$ were associated with the redoxrelated genes. Twenty-two $(40.7 \%)$ of the 54 genes predominantly identified in cEOC were involved in downstream targets of HNF-1ß.

involved in oxidative stress and inflammation, indicating that this cancer specifically expresses stress-response genes (14). These data allow us to speculate that retrograde menstruation or ovarian hemorrhage carries highly pro-oxidant factors, such as heme and iron, into the peritoneal cavity or ovarian endometrioma. Even a histologically normal ectopic endometrium might bear genetic damage caused by oxidative stress. DNA damage or loss of heterozygosity $(\mathrm{LOH})$ caused by oxidative stress may be a critical factor in the carcinogenic process. These data support the hypothesis that several significant common pathways observed in cEOC overlap the datasets identified in genes involved in oxidative stress and detoxification pathway.

\section{Pro-oxidative and antioxidative balance in cEOC}

Reactive oxygen species (ROS) include superoxide anion, hydrogen peroxide, and hydroxyl radicals (15). Oxidative stress results when production of ROS exceeds the capacity of cellular antioxidant defenses to remove these toxic ROS (16). Excess ROS can cause oxidative stress leading to damage to proteins, lipid, DNA, cell membrane, and cells by numerous carcinogenic DNA mutations or loss $(17,18)$. ROS function as a second messenger of signal transduction involved in inflammation, cell cycle, signal transduction, coagulation, fibrinolysis, extracellular matrix turnover, and can subsequently injure the cells (19). Oxidative stress has been implicated in a variety of human diseases, including cancer, atherosclerosis, diabetes, cardiovascular disorders, neurodegenerative diseases, pulmonary fibrosis, liver diseases, AIDS, and aging (20).

Epidemiological studies have linked environmental factors such as diet and lifestyle to these disorders. The number of studies reporting adverse effects of oxidative stress on several types of cancer is growing rapidly (21). Oxidative stress 
Table I. The genes highly expressed in clear cell carcinoma of the ovary.

\begin{tabular}{|c|c|}
\hline Biological process & Genes highly express \\
\hline \multicolumn{2}{|l|}{ Detoxification } \\
\hline GLRX & Glutaredoxin (thioltransferase) \\
\hline GPx3 & Glutathione peroxidase 3 \\
\hline TST & Thiosulfate sulfurtransferase (rhodanese) \\
\hline ANXA4 & Annexin A4 \\
\hline SOD2 & Superoxide dismutase 2 \\
\hline NNMT & Nicotinamide N-methyltransferase \\
\hline ANXA4 & Annexin A4 \\
\hline UGT1A1 & UDP-glycosyltransferase 1 family polypeptide $A$ \\
\hline AKR1C1 & Aldo-keto reductase family 1 , member $\mathrm{C} 1$ \\
\hline $\mathrm{ABCC} 3$ & ATP-binding cassette, sub-family C (CFTR/MR \\
\hline $\mathrm{ABCF} 2$ & ATP-binding cassette, sub-family F (GCN20), $\mathrm{m}$ \\
\hline SLC16A3 & Solute carrier family 16 member 3 (monocarbox \\
\hline \multicolumn{2}{|l|}{ Protease } \\
\hline DPPIV & Dipeptidyl peptidase IV \\
\hline ACE2 & Angiotensin converting enzyme 2 \\
\hline Collectrin & Collectrin \\
\hline TFPI2 & Tissue factor pathway inhibitor 2 \\
\hline TIMP-1 & Tissue inhibitors of metalloproteinase- 1 \\
\hline MMP & Matrix metalloproteinase \\
\hline NP & Nucleoside phosphorylase \\
\hline PTPRM & Protein tyrosine phosphatase, receptor type, $\mathrm{M}$ \\
\hline NEU3 & $\mathrm{N}$-acetyl- $\alpha$-neuraminidase 3 \\
\hline
\end{tabular}

Signal

MAP3K5/ASK1

Mitogen-activated protein kinase kinase kinase 5/apoptosis signal-regulating kinase 1

mTOR

NDRG1

RHOB/ARHB

mammalian target of rapamycin

$\mathrm{N}$-myc downstream regulated gene 1

Ras homolog gene family, member B

SCCE/SLPI

Ack1

Stratum corneum chymotryptic enzyme

Activated Cdc42-associated kinase

WWOX

WW domain-containing oxidoreductase

Adhesion

Ephrin-B1

MUC1

Galectin-3

hKIM-1

SP17

Ephrin-B1

Tumor-associated protein mucin 1

Galectin-3

Human kidney injury molecule-1

Sperm protein 17

Transcription factor

HNF-1ß

Hepatocyte nuclear factor- $1 \beta$

Octamer4

PAX8

Octamer-binding transcription factor 4

PLK/Emil

Paired box gene 8

Polo-like kinases/early mitotic inhibitor-1

$\begin{array}{ll}+ & + \\ + & + \\ + & + \\ + & + \\ + & + \\ + & + \\ + & + \\ + & + \\ + & \\ + & \\ + & \\ + & \end{array}$

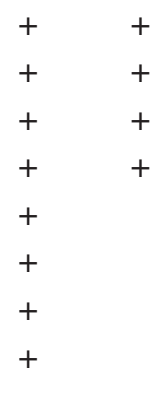

Metabolism

G6Pase

Glucose-6-phosphatase

GK

Glucokinase

GLUT2

Glucose transporter type 2

ALDOB

Aldolase B

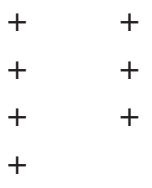


Table I. Continued.

\begin{tabular}{|c|c|c|c|}
\hline Biological process & Genes highly expressed in CCC & A & $\mathrm{B}$ \\
\hline \multicolumn{4}{|l|}{ Cell cycle } \\
\hline Cyclin E & Cyclin E & + & \\
\hline KIFC3 & Kinesin family member C3 & + & \\
\hline $\mathrm{P} 21$ & Cyclin-dependent kinase inhibitor 1A & + & \\
\hline \multicolumn{4}{|l|}{ Matrix } \\
\hline OPN & Osteopontin & + & + \\
\hline LN-5 & Laminin-5 & + & \\
\hline COL4A2 & Collagen, type IV, $\alpha 2$ & + & \\
\hline \multicolumn{4}{|l|}{ Channel } \\
\hline FXYD2 & FXYD domain-containing ion transport regulator 2 & + & + \\
\hline \multicolumn{4}{|l|}{ Growth factor } \\
\hline FGFR4 & Fibroblast growth factor receptor 4 & + & \\
\hline \multicolumn{4}{|l|}{ Suppressor } \\
\hline BRCA1 & Tumor suppressor gene & + & \\
\hline \multicolumn{4}{|l|}{ Repair } \\
\hline ERCC1/XPB & Excision repair cross-complementing & + & \\
\hline \multicolumn{4}{|l|}{ Microtubule } \\
\hline ß-tubulin cIII & ß-tubulin class III & + & \\
\hline \multicolumn{4}{|l|}{ Oncogene } \\
\hline TPD52 & Tumor protein D52 & & \\
\hline \multicolumn{4}{|l|}{ Immunity } \\
\hline B7-H4 & V-set domain containing $\mathrm{T}$ cell activation inhibitor 1 & & \\
\hline
\end{tabular}

The genes highly expressed in cEOC that have been identified by microarray gene expression profiling $(8,12)$. A, oxidative stress-related genes; and B, downstream targets of HNF-1B.

contributes to tumor initiation, development and progression by inducing genomic instability. ROS are initially regulated by the action of antioxidants which convert ROS into an inactive state. Carcinogenesis is associated with oxidative stress due to elevation of ROS or insufficient ROS detoxification. Therefore, to protect chronic oxidative stressinduced genetic instability and subsequent cell damage, cells can constitutively express genes that neutralize ROS and repair and replace the damage caused by ROS (17). The representative antioxidant proteins identified in the cEOC include glutathione $\mathrm{S}$-transferases, peroxidases, and superoxide dismutases, and activation of protective genes, including those encoding the heat shock proteins $(8,12,13,22)$.

On the contrary, enhanced antioxidant mechanisms have been implicated in chemoresistance and lead to poor prognosis (23). ROS effects can be silenced by high concentrations of antioxidants, whereas in some cells with damaged mitochondria, the opposite effect is possible (24). Interestingly, antioxidant expression is sometimes correlated to higher tumor grade/stage, chemotherapy/radiation resistance, and poor prognosis (25). Elevation in the expression of anti-oxidant SOD2 is associated with an increased frequency of tumor invasion and metastasis in certain cancers (26). These data suggest that significant impairment of the redox balance contribute to the development of an aggressive subset of primary cEOC.

In this review, we for the first time shed more light on their roles in the redox system in cEOC. The present review revealed that the following are the representative genes involved in oxidative stress and detoxification in cEOC.

\section{Genes involved in oxidative stress and detoxification in $\mathbf{C E O C}$}

Transcription factors. We explore the possibility that the following transcription factors are involved in oxidative stress. Included are HNF-1ß, polo-like kinase (PLK), octamer-binding transcription factor (Oct), and paired box gene 8 (PAX8). 
Hepatocyte nuclear factor-1 $\beta(H N F)$. At the stage of liver and renal development, differentiating cells acquire the induction of HNF target genes encoding proteins required for cell proliferation, differentiation, gluconeogenesis, and glycogen synthesis (27). A central role for HNF-1 in controlling cell proliferation, anti-apoptosis, and glucose homeostasis was established in the study by using an HNF-1null mouse model (28). Other than cell differentiation and glucose regulation, the previous studies have demonstrated the HNF-specific biological function. For examples, HNF-1 plays a role in liver gene regulation via oxidative stress during Hepatitis $\mathrm{C}$ virus infection. Hepatitis $\mathrm{C}$ virus is known to induce hepatic oxidative stress (29). Oxidative stress associates with gene reprogramming and activation of some transcription factors, in particular HNF and nuclear factor $-\kappa B(N F-\kappa B)$. Viral and bacterial infection-mediated oxidative stress induce antioxidant proteins via activation of $\operatorname{HNF}(29,30)$, suggesting that HNF-1 affects and promotes the integrity of the cellular defense system against oxidative stress (31). A redox-sensitive kinase pathway targets HNF-4 $\alpha$ to augment iNOS expression via activation of HNF-1. Nitric oxide (NO) serves antioxidant functions in settings characterized by oxidative stress such as sepsis (30). Interestingly, Liu et al have reported that downregulation of HNF-1ß expression in ovarian cancer cells increased cisplatin- or paclitaxel-mediated cytotoxicity (32). However, the redox-sensitive mechanisms regulating HNF-1 expression in cancer are largely unknown.

Polo-like kinase (PLK). HNF can induce upregulation of PLK expression through the Forkhead box (Fox) family of transcription factors (33). PLK is involved in the regulation of DNA damage checkpoint as well as in M-phase function (34). It binds to chromatin and suppresses the ATM (ataxia telangiectasia-mutated)/ATR (ATM-Rad3-related)-dependent intra-S-phase checkpoint (35). Genotoxic stresses including ROS activate PLK through Chk2 (34), promoting genome stability by regulating DNA replication under stressful conditions $(35,36)$. Thus, PLK is required for mitosis progression under oxidative stress (35).

Octamer-binding transcription factor (Oct). Oct gene is expressed as early as in the preimplantation embryo and may regulate early events of murine development (37). This transcription factor recognizes cellular stress. Oct-deficient fibroblasts were hypersensitive to hydrogen peroxide and harbored elevated ROS (38), suggesting that Oct modulates the activity of genes important for the cellular response to oxidative stress. Thus, Oct may play an important role in controlling gene expression under the oxidative stress condition. The human UDP glucuronosyltransferase (see below), UGT2B7, promoter activity was stimulated by cotransfection with HNF-1 $\alpha$ and Oct-1 simultaneously (39).

Paired box gene 8 (PAX8). PAX8, a nuclear protein, is involved in thyroid development and expression of thyroidspecific genes. Mutations in this gene have been associated with thyroid carcinomas. It is also involved in early nephrogenesis during embryogenesis, together with HNF-1ß (40). PAX8 is one of the ROS scavenging proteins and controls the intracellular redox state by inhibiting the ROS production (41). PAX8 DNA-binding activity has been controlled by Ref-1 (redox effector factor 1) (42), which protects cells from oxidative stress $(41,43)$.
Adhesion. Some of the HNF-1ß target genes are related to cell adhesion. These are ephrin, tumor-associated protein mucin 1 (MUC1), galectin-3, human kidney injury molecule (hKIM-1), and sperm protein 17 (SP17).

Ephrin. Ephrin B was upregulated in an alteration of genes related to oxidative stress (44).

Tumor-associated protein mucin 1 (MUC1). MUC1, overexpressed by human carcinomas, regulates FOXO3a (forkhead box O3a), a member of the forkhead family of transcription factors. This mucin confers a protective function against oxidative stress-induced apoptosis possibly through suppression of activation of the PI3K-Akt pathway. MUC1 thus induces oxidant scavenging and DNA repair (45).

Galectin-3. Galectin-3 is a galactoside-binding protein implicated in induction of oxidative stress, production of proinflammatory cytokines and ROS production, an ischemicreperfusion injury, apoptosis, promotion of neutrophil adhesion, mastocyte migration and degranulation $(46,47)$. Upregulation of this protein is necessary for regulation of unique sets of genes involved in tumor progression. Galectin-3 binds cancer cell surface MUC1, causing clustering of MUC1 and promoting cancer cell adhesion to endothelium (48). Thus, galectin-3 might play a role in oxidative stress, carcinogenesis and malignant transformation $(46,47)$.

Human kidney injury molecule (hKIM-1). Oxidative stress is involved in nephrotoxicity (49), which was associated with upregulation of several candidate genes including kidney molecule injury (KIM-1/Havcr1), osteopontin (Spp1), fibrinogen- $\alpha$ polypeptide (Fga), insulin-like growth factor binding protein $1(\operatorname{Igfbp} 1)$, and glutathione S-transferase (Gst) (50). Some investigators highlighted the importance of ROS in renal pathophysiology and the intriguing possibility for a role of antioxidants in the prevention of and/or protection from renal injury (51).

Sperm protein 17 (SP17). SP17 plays a role in the metastasis and resistance of cEOC to chemotherapy (52).

Signal. A majority of genes related to signal transduction pathways are target genes of HNF-1ß. These are mammalian target of rapamycin (mTOR), activated Cdc42-associated kinase (Ack1), WW domain-containing oxidoreductase (WWOX), N-myc downstream regulated gene 1 (NDRG1), ras homolog gene family (RHOB/ARHB), and stratum corneum chymotryptic enzyme (SCCE/SLPI).

mammalian target of rapamycin (mTOR). $\mathrm{H}_{2} \mathrm{O}_{2}$ induces phosphorylation state of the kinases mTOR, Akt, GSK-3ß and ERK1/ERK2, suggesting that $\mathrm{H}_{2} \mathrm{O}_{2}$ alone regulates cell apoptosis $(53,54)$.

Activated Cdc42-associated kinase (Ackl). Ack1 is a $\mathrm{Cdc} 42$-regulated kinase. Its overexpression is associated with tumorigenesis (55).

WW domain-containing oxidoreductase (WWOX). Wwox is an Ack1 interacting partner and participates in a number of cellular processes including tumor growth (56).

$N$-myc downstream regulated gene 1 (NDRG1). ROS may trigger signaling pathways resulting in the activation of the hypoxia-inducible factor (HIF)-1 transcription factor and up-regulation of hypoxia-related genes (57). NDGR1, also a downstream target of HIF-1, is induced by cell stress 
conditions, such as DNA damage and hypoxia and is overexpressed in cancer hypoxia (58).

Ras homolog gene family (RHOB/ARHB). Ras homolog gene family, member B (Rhob) is one of the hypoxia-related gene family (59).

Stratum corneum chymotryptic enzyme (SCCE/SLPI). The stratum corneum chymotryptic enzyme (SCCE) is a serine protease of the kallikrein family. Increased expression of SCCE in keratinocytes after ultraviolet B (UVB) irradiation contributes to desquamation of the stratum corneum (60). UVB-induced DNA damage and oxidative stress play an important part in this.

Protease. The following proteases are involved in oxidative stress. These are dipeptidyl peptidase IV (DPPIV), angiotensin converting enzyme 2 (ACE2), collectrin, matrix metalloproteinase (MMP), tissue inhibitors of metalloproteinase-1 (TIMP-1), nucleoside phosphorylase (NP), and protein tyrosine phosphatase, receptor type, M (PTPRM).

Dipeptidyl peptidase IV (DPPIV). DPPIV is a downstream target of HNF-1ß. The management of type 2 diabetes mellitus focuses on correcting dysglycaemia to reduce risk for vascular complications, possibly by reducing glucose-mediated oxidative stress. Apart from the currently used antidiabetic agents such as insulin, a number of new therapeutic agents are undergoing clinical development, including DPPIV inhibitors (sitagliptin and vildagliptin) (61).

Angiotensin converting enzyme 2 (ACE2). The cardiomyopathy in ACE2 null mice is related to increased oxidative stress and neutrophil infiltration (62), suggesting that ACE2 suppresses oxidative stress-mediated cardiomyopathy, neutrophil infiltration, and mitogen-activated protein kinase (MAPK) activation.

Collectrin. Heterozygous HNF-1 mutations cause pancreatic-islet $\beta$-cell dysfunction and monogenic diabetes (maturity-onset diabetes of the young subtype 3, MODY3). Collectrin is downregulated in MODY3 (63). The collectrin knockout mice exhibit increased insulin sensitivity. There is accumulating evidence of ROS-induced damage in insulin resistant cardiomyopathy (63).

Matrix metalloproteinase (MMP). Matrix metalloproteinase-2 (MMP-2), MMP-9, and urokinase-type plasminogen activator (uPA) are important factors for cancer invasion and metastasis. Association between pathogenesis of the cancer and oxidative stress has been well recognized. Oxidative stress affects several functions in cancer cells, such as cell proliferation, promotion of genetic instability, alterations in cellular sensitivity to anticancer agents, invasion, and metastasis through activation of MMPs (64).

Tissue inhibitors of metalloproteinase-1 (TIMP-1). ROS influence the balance of MMP and tissue inhibitors of matrix metalloproteinases (TIMP) (65). Oxidative stress mediates cardiomyopathy by stimulating transforming growth factor (TGF)- 11 expression, possibly via upregulation of TIMP expression (66). TIMP-1 can also serve as an indicator of endothelial dysfunction in an animal model of oxidative injury (67).

Nucleoside phosphorylase (NP). The role of nucleoside phosphorylase (NP) is to cleave inosine, deoxyinosine, guanosine, and deoxyguanosine to their corresponding base and sugar 1-phosphate. Data exist suggesting the possibility of a connection between NP and glutamateinduced cell death through oxidative stress-related signaling cascade (68).

Protein tyrosine phosphatase, receptor type, $M$ (PTPRM). The non-receptor protein-tyrosine phosphatases (PTPs) have been implicated as negative regulators of multiple signaling pathways including receptor-tyrosine kinases (69). For example, PTPs inhibit the function of the HGF receptor, the Met receptor-tyrosine kinase. HGF can inhibit HNF-induced gluconeogenesis through upregulation of phosphoenolpyruvate carboxykinase (PEPCK) and glucose-6-phosphatase (G6Pase) gene expression (70).

Detoxification. The results of our review strongly showed an overlap of the proteins involved in the redox regulation and the HNF-1ß downstream targets specifically detected in cEOC. Detoxification family proteins are involved in various biologic processes by regulating the response to oxidative stress (71). Anti-oxidative and redox-sensitive genes include glutaredoxin (GLRX), glutathione peroxidase 3 (GPx3), thiosulfate sulfurtransferase (rhodanese) (TST), superoxide dismutase 2 (SOD2), ATP-binding cassette, subfamily C (CFTR/MRP), member 3 (ABCC3), ATP-binding cassette, subfamily F (GCN20), member 2 (ABCF2), solute carrier family 16 member 3 (monocarboxylate transporter) (SLC16A3), and annexin A4 (ANXA4).

Glutaredoxin (GLRX), glutathione peroxidase 3 (GPX3), thiosulfate sulfurtransferase (rhodanese) (TST), and superoxide dismutase 2 (SOD2). They play a central role in eliminating oxidative stress (71). The GSH/glutaredoxin (GRX) system is predominantly involved in the redox regulation in cEOC. This system protects cells from $\mathrm{H}_{2} \mathrm{O}_{2}$ induced apoptosis (72). Many antioxidative and redox enzyme genes are overexpressed and aggressively protect cancer development and progression (73). However, a certain glutaredoxin, nucleoredoxin (NRX), has been reported to regulate the $\mathrm{Wnt} / ß$-catenin pathway, which promotes cell survival and progression (74).

ATP-binding cassette, sub-family C (CFTR/MRP), member 3 (ABCC3), ATP-binding cassette, sub-family $F$ (GCN20), member 2 (ABCF2), solute carrier family 16 member 3 (monocarboxylate transporter) (SLC16A3), and annexin A4 (ANXA4). The ROS-induced injury upregulates annexin A4 (75). ATP binding cassette (ABC) transporters are ATP-dependent membrane proteins predominantly expressed in liver, intestine, kidney, and placenta (76). ABC transporters protect the cells by pumping out toxicants and harmful products of oxidative stress (76). The toxic metals including $\mathrm{Fe}^{2+}$ can be also exported from the cells (77).

Others. The following genes are also involved in oxidative stress. These include excision repair cross-complementing (ERCC1/XPB), cyclin E, kinesin family member C3 (KIFC3), cyclin-dependent kinase inhibitor 1A (p21), ß-tubulin class III, osteopontin (OPN), laminin-5 (LN-5), collagen, type IV, $\alpha 2$ (COL4A2), fibroblast growth factor receptor 4 (FGFR4), and BRCA1 tumor suppressor gene.

Excision repair cross-complementing (ERCC1/XPB). The nucleotide excision repair enzyme ERCC1/XPG protein has 
DNA glycosylase activity on DNA substrates containing oxidized pyrimidine residues (78).

Cyclin E. Oxidative stress induces cell proliferation and differentiation. Oxidative stress resulted in expression of cyclin E, CDK2, p53 and p21 proteins, suggestive of deregulated cell cycle and genomic instability.

Kinesin family member $C 3(K I F C 3)$. Kinesin is a microtubule-dependent intracellular motor involved in the transport of organelles, vesicles, proteins, and RNA to specific destinations (79). This protein uses chemical energy from ATP to create movement within cells. SOD leads to an increase in expression of kinesin protein.

Cyclin-dependent kinase inhibitor 1A (p21).p21 mediates the p53-dependent cell cycle G1 phase arrest in response to a variety of stress stimuli including oxidative stress. The expression of Bax, p53 and p21(WAF1/CIP1) increased, whereas the expression of $\mathrm{Bcl}-2$ decreased in tumor cells treated with $\mathrm{H}_{2} \mathrm{O}_{2}$.

$\beta$-tubulin class III. The microtubules are dynamic polymers composed of tubulin heterodimers, and they form the mitotic spindles, which are known to introduce the replicated DNA molecules to the respective daughter cell (80). B-tubulin class III has been discovered as a marker of drug resistance in human cancer.

Osteopontin $(O P N)$. Osteopontin modulates inflammation, oxidative stress, and fibrosis. It is a secreted glycoprotein that has been implicated in several renal pathological conditions such as those due to oxidative stress, ischemia and toxicity (81).

Laminin-5 (LN-5). Oligodendrocyte death occurs in many disorders of the central nervous system, including multiple sclerosis and brain trauma through oxidative stress (82). Astrocytes promote oligodendrocyte survival through a mechanism involving the interaction of integrin on oligodendrocytes with laminin on astrocytes.

Collagen, type IV, a2 (COL4A2). Bone morphogenetic protein-7 (BMP-7) protects kidneys from oxidative stress involved in diabetic nephropathy (83). BMP-7 also protects mesangial cells from oxidative stress. The antioxidative activity of BMP-7 was due to inhibition of some signaling pathways including $\mathrm{PKC}, \mathrm{JNK}$, and c-jun activation, which results in modification of collagen type IV expression (83).

Fibroblast growth factor receptor 4 (FGFR4). Oxidative stress is an important factor in the pathogenesis of bronchopulmonary dysplasia in infants, possibly due to upregulation of fibroblast growth factor receptor-4 (FGFR4) (84).

BRCA1 tumor suppressor gene. The breast cancer suppressor BRCA1 stimulates antioxidant gene expression and protects cells against oxidative stress (85).

\section{Specific expression of HNF-1ß and its downstream targets in cEOC}

cEOC are often associated with endometriosis (9). Recent studies have noted specific expression of HNF-1ß in endometriosis and CCC, suggesting that early differentiation into the clear cell lineage takes place in the endometriosis $(8,86)$. Several significant common pathways observed in cEOC overlap the datasets identified in genes involved in HNF-1ß and its downstream pathway (8) (Table I and Fig. 1). Twenty- two $(40.7 \%)$ of the 54 genes predominantly identified in cEOC were involved in downstream targets of HNF-1ß $(8,12,13)$. A redox-sensitive subset of cEOC genes linked to oxidative and detoxification pathways was identified and associated with HNF-1ß-specific downstream targets.

HNF is a homeobox transcription factor that functions during human embryogenesis (87). HNF-1ß is expressed in the liver and kidneys and plays an important role in organogenesis of the urogenital system (88). It is thought that HNF-1ß induces anti-apoptosis, glycogen storage, and detoxification through transactivation of its target genes (8). We summarize that, at the cellular level, HNF-1ß has been presumed as a common protective mechanism in the oxidative stress situations.

Several genes have been reported to be upregulated by HNF-1ß. These include nicotinamide N-methyltransferase (NNMT), Annexin A4 (ANXA4), UDP-glycosyltransferase 1 family polypeptide A1 (UGT1A1), FXYD domain-containing ion transport regulator 2 (FXYD2), tissue factor pathway inhibitor 2 (TFPI2), mitogen-activated protein kinase kinase kinase 5/apoptosis signal-regulating kinase 1 (MAP3K5/ ASK1), glucose-6-phosphatase (G6Pase), glucokinase (GK), glucose transporter type 2 (GLUT2), and mTOR.

Nicotinamide $\mathrm{N}$-methyltransferase (NNMT). N-methylation is one method by which drugs are metabolized and detoxified by the liver. NNMT is responsible for this enzymatic activity. $\mathrm{HCV}$-related core protein may play a role in the pathogenesis of fibrosis and hepatocellular carcinoma (89). HCV infection can produce excess amount of core protein in hepatocytes, which leads to oxidative stress, and subsequently upregulates NNMT, one of the cellular antioxidant defense mechanisms.

Annexin A4 (ANXA4). ANXA4 belongs to the annexin family of calcium-dependent phospholipid binding proteins. Oxidative stress induces specific upregulation in ANXA4 expression that may be critical for the induction of apoptosis and necrosis by d-galactosamine in cultured human hepatocytes (75).

UDP-glycosyltransferase 1 family polypeptide AI (UGT1A1). UGT1A1 is an enzyme of the glucuronidation pathway that transforms small lipophilic molecules into water-soluble, excretable metabolites. Oxidative stress induces UGT1A1 through the Nrf2-Keap1-dependent signaling pathway (90).

FXYD domain-containing ion transport regulator 2 (FXYD2). The gene nomenclature for the family is FXYDdomain containing ion transport regulator. FXYD2 is known as the gamma subunit of the $\mathrm{Na}, \mathrm{K}$-ATPase, which regulates the properties of that enzyme. FXYDs play a role as components of Na-K-ATPase to cellular stress (91).

Tissue factor pathway inhibitor 2 (TFPI2). The presence of chronic viral hepatitis is a novel determinant of the increased oxidative stress as well as the disturbances of coagulation/ fibrinolysis (TF/TFPI) system in haemodialysis patients (92).

Mitogen-activated protein kinase kinase kinase 5/apoptosis signal-regulating kinase 1 (MAP3K5/ASK1). Apoptosis signalregulating kinase 1 (ASK1) is a member of the mitogenactivated protein kinase kinase kinase family, which activates c-Jun $\mathrm{N}$-terminal kinase and p38 in response to a diverse array of stresses such as oxidative stress (93). 
Glucose-6-phosphatase (G6Pase). Glucose-6-phosphatase (G6Pase) is located in the endoplasmic reticulum and catalyzes hydrolysis of G6P to glucose and phosphate. G6Pase was susceptible to inactivation by iron, and was an excellent marker for oxidative stress (94).

Glucokinase (GK). Glucose metabolism was increased in pancreatic $\beta$ cells by enhancing glucokinase (GK) activity (95). Increased glucose metabolism generates oxidative stress and impairs cell function and survival.

Glucose transporter type 2 (GLUT2). GLUT2 is also known as a SLC2A2 solute carrier family 2. Oxidative stress may contribute to the deterioration of $\beta$-cell function found in diabetes (96). Insulin, GLUT2, and GK are $\beta$-cell-specific genes.

mTOR. Although there are no data on the direst role of HNF-1ß in mTOR signaling, mTOR kinase and signalling through mTOR are highly sensitive to suppression of HNF-1 $\alpha$ function (97).

\section{Conclusions}

Herein we review the role of redox-dependent signaling pathways and transcription factor $\mathrm{HNF}-1 \beta$ that might regulate tumorigenesis of cEOC. Oxidative stress contributes to tumor initiation and progression solely by inducing genomic instability via direct interactions of a prolonged exposure to oxidative stress (98). Recent studies indicate that ROS are upregulated in tumors and can lead to aberrant induction of signaling networks that cause tumorigenesis and metastasis (21). Common molecular mechanisms may exist in oxidative stress-induced carcinogenesis, since the localization of oxidative DNA damage is not random (21). The carcinogenicity of iron has been demonstrated in animal models, and epidemiologic studies have shown associations with several human cancers. Free iron is a pro-oxidant and can induce oxidative stress and DNA damage. For example, excess body iron stores or elevated dietary iron intake may increase the likelihood that free iron contributes to increased risk of breast cancer (99). In animal models, iron induces oxidative damage, which subsequently leads to renal cell carcinoma (RCC) (100). Furthermore, exposure to asbestos fibers has been associated with malignant mesothelioma in humans. Phagocytic cells that engulf asbestos fibers produce large amounts of free radicals and iron-containing asbestos fibers appear more carcinogenic (101). Therefore, the ironmediated oxidative stress is considered to be a pathogenesis of cEOC.

Ovarian hemorrhage carries highly pro-oxidant factors, such as blood containing iron into the ovarian endometrioma (102). Severe hemolysis occurring during the development of endometriosis results in high levels of free iron $(14,22)$. Several important endometriosis-specific genes overlap with those known to be regulated by iron (8). Iron may have a significant impact on endometriotic cell gene expression. It has been experimentally shown for the first time that abundant free iron in the contents of endometriotic cysts was associated with oxidative stress and subsequent DNA damage (102). Clinical observation suggests that the most important and specific causal factor for the development of cEOC may be an exposure to blood for a long latency period $(9,14)$. The molecular pathology of cEOC may involve genetic alteration by iron-induced oxidative stress. In fact, several multigene families of carcinogenesis, progression and developmental control genes have been identified (Table I). The question is what is the main modulator of this disorder. The specific genes upregulated in cEOC were HNF-1ß, DPPIV, osteopontin, ACE2, FXYD2, TFPI2, NNMT, LITAF/PIG7, RBPMS, ANXA4, UGT1A1, GLRX, ASK1, G6Pase, GLUT2, and GK (8). The possible genes included in the profiles of HNF-1ß target genes are DPPIV, osteopontin, ACE2, FXYD2, TFPI2, NNMT, LITAF/PIG7, RBPMS, ANXA4, and UGT1A1 (Table I,B). Therefore, the majority of the genes upregulated in cEOC are HNF-1ß and its downstream targets, suggesting that HNF-1ß is a distinct molecular signature for pathophysiology of cEOC. HNF-1ß has been implicated in the regulation of detoxification, glycogen accumulation, and survival. The findings of this review are not only of fundamental importance in the understanding of the pathophysiology of cEOC, but also essential for the development of new therapeutic strategies.

It became apparent that oxidative stress can initiate cell demise by apoptosis, but also prevent cell death by provoking adaptive responses that, in turn, facilitate cell proliferation or angiogenesis, thus contributing to tumor progression. In the vast majority of endometriotic cells, the context of genetic alterations will shape the role of oxidative stress to affect susceptibility of cells to undergo oxidative stress-induced cell death. However, the remaining endometriotic cells implying the acquisition of resistance to cell death allow adaptation and progression towards malignancy. Targeting of oxidative stress may be an effective strategy to overcome carcinogenesis and progression of cEOC. In cEOC, a number of defense systems have evolved to combat the accumulation of iron-induced oxidative stress (70).

Several antioxidants have been developed to prevent carcinogenesis and cancer progression and are currently in clinical studies. In the experimental studies, antioxidants including vitamins, $B$-carotene, and selenium may reduce oxidative damage and prevent cancer (103). However, clinical studies showed that antioxidant supplements do not exert any significant effects against the development of cancer. There are additional compounds which afforded protection against induced oxidative stress, most probably by means of an iron-chelating mechanism. These include a phenolic compound (o-phenanthroline) (104), a novel metal chelator (Tachpyr, N,N'N"'-tris(2-pyridylmethyl)-cis,cis-1,3,5triaminocyclohexane) (105), flavonoid (106), which offer a possibility for overcoming oxidative stress and subsequent carcinogenesis. Since iron-induced oxidative stress and inefficient repair could be related to DNA damage and probably to carcinogenesis, modulation of these processes by antioxidants might be relevant in further prevention of cEOC. These candidates warrant further study for use in risk assessment and/or as therapeutic targets in cEOC.

\section{Acknowledgements}

This work was supported by a grant-in-aid for Scientific Research from the Ministry of Education, Science and Culture of Japan (to H.K.). 


\section{References}

1. Roh MH, Kindelberger D and Crum CP: Serous tubal intraepithelial carcinoma and the dominant ovarian mass: clues to serous tumor origin? Am J Surg Pathol 33: 376-383, 2009.

2. Kurman RJ, Visvanathan K, Roden R, Wu TC and Shih IeM: Early detection and treatment of ovarian cancer: shifting from early stage to minimal volume of disease based on a new model of carcinogenesis. Am J Obstet Gyneco 198: 351-356, 2008.

3. Sato N, Tsunoda H, Nishida M, Morishita Y, Takimoto Y and Kubo T: Loss of heterozygosity on 10q23.3 and mutation of the tumor suppressor gene PTEN in benign endometrial cyst of the ovary: possible sequence progression from benign endometrial cyst to endometrioid carcinoma and clear cell carcinoma of the ovary. Cancer Res 60: 7052-7056, 2000.

4. Moreno-Bueno G, Gamallo C, Perez-Gallego L, de Mora JC, Suarez A and Palacios J: beta-Catenin expression pattern, betacatenin gene mutations, and microsatellite instability in endometrioid ovarian carcinomas and synchronous endometrial carcinomas. Diagn Mol Pathol 10: 116-122, 2001.

5. Auner V, Kriegshäuser G, Tong D, Horvat R, Reinthaller A, Mustea A and Zeillinger R: KRAS mutation analysis in ovarian samples using a high sensitivity biochip assay. BMC Cancer 9: $111,2009$.

6. Quaye L, Song H, Ramus SJ, Gentry-Maharaj A, Høgdall E, DiCioccio RA, McGuire V, Wu AH, Van Den Berg DJ, Pike MC, Wozniak E, Doherty JA, Rossing MA, Ness RB, Moysich KB, Høgdall C, Blaakaer J; Ovarian Cancer Association Consortium, Easton DF, Ponder BA, Jacobs IJ, Menon U, Whittemore AS, Krüger-Kjaer S, Pearce CL, Pharoah PD and Gayther SA: Tagging single-nucleotide polymorphisms in candidate oncogenes and susceptibility to ovarian cancer. Br J Cancer 100: 993-1001, 2009.

7. Kuo KT, Mao TL, Jones S, Veras E, Ayhan A, Wang TL, Glas R, Slamon D, Velculescu VE, Kuman RJ and Shih IeM: Frequent activating mutations of PIK3CA in ovarian clear cell carcinoma. Am J Pathol 174: 1597-1601, 2009.

8. Kobayashi H, Yamada Y, Kanayama S, Furukawa N, Noguchi T, Haruta S, Yoshida S, Sakata M, Sado T and Oi H: The role of hepatocyte nuclear factor-1beta in the pathogenesis of clear cell carcinoma of the ovary. Int J Gynecol Cancer 19: 471-479, 2009

9. Kobayashi H, Sumimoto K, Kitanaka T, Yamada Y, Sado T, Sakata M, Yoshida S, Kawaguchi R, Kanayama S, Shigetomi H, Haruta S, Tsuji Y, Ueda S and Terao T: Ovarian endometriomarisks factors of ovarian cancer development. Eur J Obstet Gynecol Reprod Biol 138: 187-193, 2008

10. Yamamoto S, Tsuda H, Takano M, Hase K, Tamai S and Matsubara O: Clear-cell adenofibroma can be a clonal precursor for clear-cell adenocarcinoma of the ovary: a possible alternative ovarian clear-cell carcinogenic pathway. J Pathol 216: 103-110, 2008

11. Shan W and Liu J: Epithelial ovarian cancer. Focus on genetics and animal models. Cell Cycle 8: 731-735, 2009.

12. Yoshida S, Furukawa N, Haruta S, Tanase Y, Kanayama S, Noguchi T, Sakata M, Yamada Y, Oi H and Kobayashi H Theoretical model of treatment strategies for clear cell carcinoma of the ovary: Focus on perspectives. Cancer Treat Rev, Aug 7 , 2009 (Epub ahead of print).

13. Kobayashi H, Kajiwara H, Kanayama S, Yamada Y, Furukawa N, Noguchi T, Haruta S, Yoshida S, Sakata M, Sado T and Oi H: Molecular pathogenesis of endometriosis-associated clear cell carcinoma of the ovary (Review). Oncol Rep 22: 233-240, 2009.

14. Mandai M, Yamaguchi K, Matsumura N, Baba T and Konishi I: Ovarian cancer in endometriosis: molecular biology, pathology, and clinical management. Int J Clin Oncol 14: 383-391, 2009.

15. Ames BN, Shigenaga MK and Hagen TM: Oxidants, antioxidants, and the degenerative diseases of aging. Proc Natl Acad Sci USA 90: 7915-7922, 1993.

16. Limón-Pacheco J and Gonsebatt ME: The role of antioxidants and antioxidant-related enzymes in protective responses to environmentally induced oxidative stress. Mutat Res 674: $137-147,2009$

17. Storz G and Imlay JA: Oxidative stress. Curr Opin Microbiol 2: 188-194, 1999.

18. Barnouin K, Dubuisson ML, Child ES, Fernandez de Mattos S, Glassford J, Medema RH, Mann DJ and Lam EW: $\mathrm{H}_{2} \mathrm{O}_{2}$ induces a transient multi-phase cell cycle arrest in mouse fibroblasts through modulating cyclin D and p21Cip1 expression. J Biol Chem 277: 13761-13770, 2002.
19. Davies KJ: Oxidative stress, antioxidant defenses, and damage removal, repair, and replacement systems. IUBMB Life 50: 279-289, 2000

20. Cerutti PA: Oxy-radicals and cancer. Lancet 344: 862-863, 1994.

21. Toyokuni S: Molecular mechanisms of oxidative stress-induced carcinogenesis: from epidemiology to oxygenomics. IUBMB Life 60: 441-447, 2008.

22. Kobayashi H, Yamada Y, Kanayama S, Furukawa N, Noguchi T, Haruta S, Yoshida S, Sakata M, Sado T and Oi H: The role of iron in the pathogenesis of endometriosis. Gynecol Endocrinol 25: 39-52, 2009.

23. Karihtala P and Soini Y: Reactive oxygen species and antioxidant mechanisms in human tissues and their relation to malignancies. APMIS 115: 81-103, 2007.

24. Qutub AA and Popel AS: Reactive oxygen species regulate hypoxia-inducible factor 1 alpha differentially in cancer and ischemia. Mol Cell Biol 28: 5106-5119, 2008.

25. Pedersen MØ, Larsen A, Stoltenberg M and Penkowa M: The role of metallothionein in oncogenesis and cancer prognosis. Prog Histochem Cytochem 44: 29-64, 2009.

26. Connor KM, Hempel N, Nelson KK, Dabiri G, Gamarra A, Belarmino J, Van De Water L, Mian BM and Melendez JA: Manganese superoxide dismutase enhances the invasive and migratory activity of tumor cells. Cancer Res 67: 10260-10267, 2007.

27. Parviz F, Matullo C, Garrison WD, Savatski L, Adamson JW, Ning G, Kaestner KH, Rossi JM, Zaret KS and Duncan SA: Hepatocyte nuclear factor 4alpha controls the development of a hepatic epithelium and liver morphogenesis. Nat Genet 34: 292-296, 2003.

28. Lee YH, Sauer B and Gonzalez FJ: Laron dwarfism and noninsulin-dependent diabetes mellitus in the Hnf-1alpha knockout mouse. Mol Cell Biol 18: 3059-3068, 1998.

29. Qadri I, Iwahashi M, Kullak-Ublick GA and Simon FR: Hepatocyte nuclear factor (HNF) 1 and HNF4 mediate hepatic multidrug resistance protein 2 up-regulation during hepatitis $\mathrm{C}$ virus gene expression. Mol Pharmacol 70: 627-636, 2006.

30. Guo H, Wei J, Inoue Y, Gonzalez FJ and Kuo PC: Serine/ threonine phosphorylation regulates HNF-4alpha-dependent redox-mediated iNOS expression in hepatocytes. Am J Physiol Cell Physiol 284: C1090-C1099, 2003.

31. Muppala V, Lin CS and Lee YH: The role of HNF-1alpha in controlling hepatic catalase activity. Mol Pharmacol 57: 93-100, 2000.

32. Liu P, Khurana A, Rattan R, He X, Kalloger S, Dowdy S, Gilks B and Shridhar V: Regulation of HSulf-1 expression by variant hepatic nuclear factor 1 in ovarian cancer. Cancer Res 69: 4843-4850, 2009.

33. Krupczak-Hollis K, Wang X, Kalinichenko VV, Gusarova GA, Wang IC, Dennewitz MB, Yoder HM, Kiyokawa H, Kaestner KH and Costa RH: The mouse Forkhead Box m1 transcription factor is essential for hepatoblast mitosis and development of intrahepatic bile ducts and vessels during liver morphogenesis. Dev Biol 276: 74-88, 2004

34. Xie S, Wu H, Wang Q, Kunicki J, Thomas RO, Hollingsworth RE, Cogswell J and Dai W: Genotoxic stress-induced activation of Plk3 is partly mediated by Chk2. Cell Cycle 1: 424-429, 2002.

35. Trenz K, Errico A and Costanzo V: Plx1 is required for chromosomal DNA replication under stressful conditions. EMBO J 27: 876-885, 2008.

36. Xie S, Wang Q, Wu H, Cogswell J, Lu L, Jhanwar-Uniyal M and Dai W: Reactive oxygen species-induced phosphorylation of p53 on serine 20 is mediated in part by polo-like kinase-3. J Biol Chem 276: 36194-36199, 2001.

37. Schöler HR: Octamania: the POU factors in murine development. Trends Genet 7: 323-329, 1991.

38. Tantin D, Schild-Poulter C, Wang V, Haché RJ and Sharp PA: The octamer binding transcription factor Oct-1 is a stress sensor. Cancer Res 65: 10750-10758, 2005.

39. Ishii Y, Hansen AJ and Mackenzie PI: Octamer transcription factor-1 enhances hepatic nuclear factor-1alpha-mediated activation of the human UDP glucuronosyltransferase 2B7 promoter. Mol Pharmacol 57: 940-947, 2000.

40. Wu G, Bohn S and Ryffel GU: The HNF1beta transcription factor has several domains involved in nephrogenesis and partially rescues Pax8/lim1-induced kidney malformations. Eur J Biochem 271: 3715-3728, 2004

41. Tell G, Quadrifoglio F, Tiribelli C and Kelley MR: The many functions of APE1/Ref-1: not only a DNA repair enzyme. Antioxid Redox Signal 11: 601-620, 2009. 
42. Wentzel P and Eriksson UJ: Genetic influence on dysmorphogenesis in embryos from different rat strains exposed to ethanol in vivo and in vitro. Alcohol Clin Exp Res 32: 874-887, 2008.

43. Vascotto C, Cesaratto L, Zeef LA, Deganuto M, D'Ambrosio C, Scaloni A, Romanello M, Damante G, Taglialatela G, Delneri D, Kelley MR, Mitra S, Quadrifoglio F and Tell G: Genome-wide analysis and proteomic studies reveal APE1/Ref-1 multifunctional role in mammalian cells. Proteomics 9: 1058-1074, 2009.

44. Makino H, Miyamoto Y, Sawai K, Mori K, Mukoyama M, Nakao K, Yoshimasa Y and Suga S: Altered gene expression related to glomerulogenesis and podocyte structure in early diabetic nephropathy of $\mathrm{db} / \mathrm{db}$ mice and its restoration by pioglitazone. Diabetes 55: 2747-2756, 2006.

45. Yin L, Huang L and Kufe D: MUC1 oncoprotein activates the FOXO3a transcription factor in a survival response to oxidative stress. J Biol Chem 279: 45721-45727, 2004.

46. Mazurek N, Sun YJ, Price JE, Ramdas L, Schober W, NangiaMakker P, Byrd JC, Raz A and Bresalier RS: Phosphorylation of galectin-3 contributes to malignant transformation of human epithelial cells via modulation of unique sets of genes. Cancer Res 65: 10767-10775, 2005

47. Fernandes Bertocchi AP, Campanhole G, Wang PH, Gonçalves GM, Damião MJ, Cenedeze MA, Beraldo FC, de Paula Antunes Teixeira V, Dos Reis MA, Mazzali M, Pacheco-Silva A and Câmara NO: A role for galectin-3 in renal tissue damage triggered by ischemia and reperfusion injury. Transpl Int 21: 999-1007, 2008.

48. Rhodes JM, Campbell BJ and Yu LG: Lectin-epithelial interactions in the human colon. Biochem Soc Trans 36: 1482-1486, 2008

49. Ozaki N, Matheis KA, Gamber M, Feidl T, Nolte T, Kalkuhl A and Deschl U: Identification of genes involved in gentamicininduced nephrotoxicity in rats - A toxicogenomic investigation. Exp Toxicol Pathol, Aug 5, 2009 (Epub ahead of print).

50. Dieterich C, Puey A, Lin S, Swezey R, Furimsky A, Fairchild D, Mirsalis JC and $\mathrm{Ng} \mathrm{HH}$ : Gene expression analysis reveals new possible mechanisms of vancomycin-induced nephrotoxicity and identifies gene markers candidates. Toxicol Sci 107: 258-269, 2009.

51. Ragheb A, Attia A, Eldin WS, Elbarbry F, Gazarin S and Shoker A: The protective effect of thymoquinone, an antioxidant and anti-inflammatory agent, against renal injury: A review. Saudi J Kidney Dis Transpl 20: 741-752, 2009.

52. Nakazato T, Kanuma T, Tamura T, Faried LS, Aoki H and Minegishi T: Sperm protein 17 influences the tissue-specific malignancy of clear cell adenocarcinoma in human epithelial ovarian cancer. Int J Gynecol Cancer 17: 426-432, 2007.

53. Andreucci M, Fuiano G, Presta P, Lucisano G, Leone F, Fuiano L, Bisesti V, Esposito P, Russo D, Memoli B, Faga T and Michael A: Downregulation of cell survival signalling pathways and increased cell damage in hydrogen peroxide-treated human renal proximal tubular cells by alpha-erythropoietin. Cell Prolif 42: 554-561, 2009.

54. Zhang H, Kong X, Kang J, Su J, Li Y, Zhong J and Sun L: Oxidative stress induces parallel autophagy and mitochondria dysfunction in human glioma U251 cells. Toxicol Sci 110: 376-388, 2009

55. Mahajan NP, Liu Y, Majumder S, Warren MR, Parker CE Mohler JL, Earp HS and Whang YE: Activated Cdc42-associated kinase Ack1 promotes prostate cancer progression via androgen receptor tyrosine phosphorylation. Proc Natl Acad Sci USA 104 8438-8443, 2007.

56. Del Mare S, Salah Z and Aqeilan RI: WWOX: its genomics, partners, and functions. J Cell Biochem, Aug 25, 2009 (Epub ahead of print)

57. Salnikow K, Su W, Blagosklonny MV and Costa M: Carcinogenic metals induce hypoxia-inducible factor-stimulated transcription by reactive oxygen species-independent mechanism. Cancer Res 60: 3375-3378, 2000

58. Wimmer U, Wang Y, Georgiev O and Schaffner W: Two major branches of anti-cadmium defense in the mouse: MTF-1/metallothioneins and glutathione. Nucleic Acids Res 33: 5715-5727, 2005 .

59. Avivi A, Brodsky L, Nevo E and Band MR: Differential expression profiling of the blind subterranean mole rat Spalax ehrenbergi superspecies: bioprospecting for hypoxia tolerance. Physiol Genomics 27: 54-64, 2006

60. Nin M, Katoh N, Kokura S, Handa O, Yoshikawa T and Kishimoto S: Dichotomous effect of ultraviolet B on the expression of corneodesmosomal enzymes in human epidermal keratinocytes. J Dermatol Sci 54: 17-24, 2009.
61. Dailey G: Beyond insulin replacement: addressing the additional needs of the diabetes patient. Diabetes Obes Metab 10: 83-97, 2008.

62. Oudit GY, Kassiri Z, Patel MP, Chappell M, Butany J, Backx PH, Tsushima RG, Scholey JW, Khokha R and Penninger JM: Angiotensin II-mediated oxidative stress and inflammation mediate the age-dependent cardiomyopathy in ACE2 null mice. Cardiovasc Res 75: 29-39, 2007

63. Malakauskas SM, Kourany WM, Zhang XY, Lu D, Stevens RD, Koves TR, Hohmeier HE, Muoio DM, Newgard CB and Le TH: Increased insulin sensitivity in mice lacking collectrin, a downstream target of HNF-1alpha. Mol Endocrinol 23: 881-892, 2009.

64. Kumar B, Koul S, Khandrika L, Meacham RB and Koul HK: Oxidative stress is inherent in prostate cancer cells and is required for aggressive phenotype. Cancer Res 68: 1777-1785, 2008.

65. Hemmerlein B, Johanns U, Halbfass J, Böttcher T, Heuser M, Radzun HJ and Thelen P: The balance between MMP-2/-9 and TIMP-1/-2 is shifted towards MMP in renal cell carcinomas and can be further disturbed by hydrogen peroxide. Int J Oncol 24: 1069-1076, 2004

66. Zhao W, Zhao T, Chen Y, Ahokas RA and Sun Y: Oxidative stress mediates cardiac fibrosis by enhancing transforming growth factor-beta1 in hypertensive rats. Mol Cell Biochem 317: 43-50, 2008.

67. Moore R, Hawley A, Sigler R, Farris D, Wrobleski S, Ramacciotti $\mathrm{E}$ and Myers D: Tissue inhibitor of metalloproteinase-1 is an early marker of acute endothelial dysfunction in a rodent model of venous oxidative injury. Ann Vasc Surg 23: 498-505, 2009

68. Kang TH, Bae KH, Yu MJ, Kim WK, Hwang HR, Jung H, Lee PY, Kang S, Yoon TS, Park SG, Ryu SE and Lee SC: Phosphoproteomic analysis of neuronal cell death by glutamateinduced oxidative stress. Proteomics 7: 2624-2635, 2007.

69. Sangwan V, Paliouras GN, Abella JV, Dubé N, Monast A, Tremblay ML and Park M: Regulation of the Met receptortyrosine kinase by the protein-tyrosine phosphatase $1 \mathrm{~B}$ and T-cell phosphatase. J Biol Chem 284: 34374-34383, 2008.

70. Chanda D, Li T, Song KH, Kim YH, Sim J, Lee CH, Chiang JY and Choi HS: HGF family negatively regulates hepatic gluconeogenesis via induction of orphan nuclear receptor SHP in primary hepatocytes. J Biol Chem 284: 28510-28521, 2009.

71. Bonomini F, Tengattini S, Fabiano A, Bianchi R and Rezzani R: Atherosclerosis and oxidative stress. Histol Histopathol 23: 381-390, 2008

72. Urata Y, Ihara Y, Murata H, Goto S, Koji T, Yodoi J, Inoue S and Kondo T: 17Beta-estradiol protects against oxidative stressinduced cell death through the glutathione/glutaredoxin-dependent redox regulation of Akt in myocardiac H9c2 cells. J Biol Chem 281: 13092-13102, 2006.

73. Fujii J, Iuchi Y and Okada F: Fundamental roles of reactive oxygen species and protective mechanisms in the female reproductive system. Reprod Biol Endocrinol 3: 43, 2005.

74. Funato $\mathrm{Y}$ and Miki H: Nucleoredoxin, a novel thioredoxin family member involved in cell growth and differentiation. Antioxid Redox Signal 9: 1035-1057, 2007.

75. Rodríguez-Ariza A, López-Sánchez LM, González R, Corrales FJ, López P, Bernardos A and Muntané J: Altered protein expression and protein nitration pattern during d-galactosamine-induced cell death in human hepatocytes: a proteomic analysis. Liver Int 25: $1259-1269,2005$

76. Huls M, Russel FG and Masereeuw R: The role of ATP binding cassette transporters in tissue defense and organ regeneration. J Pharmacol Exp Ther 328: 3-9, 2009.

77. Ghio AJ: Disruption of iron homeostasis and lung disease Biochim Biophys Acta 1790: 731-739, 2009

78. Klungland A, Höss M, Gunz D, Constantinou A, Clarkson SG, Doetsch PW, Bolton PH, Wood RD and Lindahl T: Base excision repair of oxidative DNA damage activated by XPG protein. Mol Cell 3: 33-42, 1999.

79. Hallmann A, Milczarek R, Lipinski M, Kossowska E, Spodnik JH, Wozniak M, Wakabayashi T and Klimek J: Fast perinuclear clustering of mitochondria in oxidatively stressed human choriocarcinoma cells. Folia Morphol (Warsz) 63: 407-412, 2004.

80. Cicchillitti L, Penci R, Di Michele M, Filippetti F, Rotilio D, Donati MB, Scambia G and Ferlini C: Proteomic characterization of cytoskeletal and mitochondrial class III beta-tubulin. Mol Cancer Ther 7: 2070-2079, 2008. 
81. Wolak T, Kim H, Ren Y, Kim J, Vaziri ND and Nicholas SB: Osteopontin modulates angiotensin II-induced inflammation, oxidative stress, and fibrosis of the kidney. Kidney Int 76: 32-43, 2009.

82. Corley SM, Ladiwala U, Besson A and Yong VW: Astrocytes attenuate oligodendrocyte death in vitro through an alpha(6) integrin-laminin-dependent mechanism. Glia 36: 281-294, 2001.

83. Yeh CH, Chang CK, Cheng MF, Lin HJ and Cheng JT: The antioxidative effect of bone morphogenetic protein-7 against high glucose-induced oxidative stress in mesangial cells. Biochem Biophys Res Commun 382: 292-297, 2009.

84. Wagenaar GT, ter Horst SA, van Gastelen MA, Leijser LM, Mauad T, van der Velden PA, de Heer E, Hiemstra PS Poorthuis BJ and Walther FJ: Gene expression profile and histopathology of experimental bronchopulmonary dysplasia induced by prolonged oxidative stress. Free Radic Biol Med 36: 782-801, 2004

85. Saha T, Rih JK and Rosen EM: BRCA1 down-regulates cellular levels of reactive oxygen species. FEBS Lett 583: 1535-1543, 2009

86. Kato N, Sasou S and Motoyama T: Expression of hepatocyte nuclear factor-1beta (HNF-1beta) in clear cell tumors and endometriosis of the ovary. Mod Pathol 19: 83-89, 2006.

87. Zaffanello M, Brugnara M, Franchini M and Fanos V: TCF2 gene mutation leads to nephro-urological defects of unequal severity: an open question. Med Sci Monit 14: RA78-RA86, 2008.

88. Kato $\mathrm{N}$ and Motoyama T: Hepatocyte nuclear factor-1beta (HNF-1beta) in human urogenital organs: its expression and role in embryogenesis and tumorigenesis. Histol Histopathol 24: 1479-1486, 2009.

89. Li K, Prow T, Lemon SM and Beard MR: Cellular response to conditional expression of hepatitis $\mathrm{C}$ virus core protein in Huh7 cultured human hepatoma cells. Hepatology 35: 1237-1246, 2002.

90. Yueh MF and Tukey RH: Nrf2-Keap1 signaling pathway regulates human UGT1A1 expression in vitro and in transgenic UGT1 mice. J Biol Chem 282: 8749-8758, 2007.

91. Arystarkhova E, Donnet C, Muñoz-Matta A, Specht SC and Sweadner KJ: Multiplicity of expression of FXYD proteins in mammalian cells: dynamic exchange of phospholemman and gamma-subunit in response to stress. Am J Physiol Cell Physiol 292: C1179-C1191, 2007.

92. Pawlak K, Zolbach K, Borawski J, Mysliwiec M, Kovalchuk O, Chyczewski L and Pawlak D: Chronic viral hepatitis C, oxidative stress and the coagulation/fibrinolysis system in haemodialysis patients. Thromb Res 123: 166-170, 2008.

93. Hattori K, Naguro I, Runchel C and Ichijo H: The roles of ASK family proteins in stress responses and diseases. Cell Commun Signal 7: 9, 2009.
94.Hu ML and Tappel AL: Glutathione and antioxidants protect microsomes against lipid peroxidation and enzyme inactivation. Lipids 27: 42-45, 1992.

95.Wu L, Nicholson W, Knobel SM, Steffner RJ, May JM, Piston DW and Powers AC: Oxidative stress is a mediator of glucose toxicity in insulin-secreting pancreatic islet cell lines. J Biol Chem 279: 12126-12134, 2004.

96. Kaneto H, Xu G, Song KH, Suzuma K, Bonner-Weir S, Sharma A and Weir GC: Activation of the hexosamine pathway leads to deterioration of pancreatic beta-cell function through the induction of oxidative stress. Biol Chem 276: 31099-31104, 2001.

97. Farrelly AM, Wobser H, Bonner C, Anguissola S, Rehm M, Concannon CG, Prehn JH and Byrne MM: Early loss of mammalian target of rapamycin complex 1 (mTORC1) signalling and reduction in cell size during dominant-negative suppression of hepatic nuclear factor 1-alpha (HNF1A) function in INS-1 insulinoma cells. Diabetologia 52: 136-144, 2009.

98. Kohchi C, Inagawa H, Nishizawa T and Soma G: ROS and innate immunity. Anticancer Res 29: 817-821, 2009.

99. Kabat GC and Rohan TE: Does excess iron play a role in breast carcinogenesis? An unresolved hypothesis. Cancer Causes Control 18: 1047-1053, 2007

100. Fukuda A, Osawa T, Oda H, Toyokuni S, Satoh K and Uchida K: Oxidative stress response in iron-induced renal carcinogenesis: acute nephrotoxicity mediates the enhanced expression of glutathione S-transferase Yp isozyme. Arch Biochem Biophys 329: 39-46, 1996.

101. Toyokuni S: Mechanisms of asbestos-induced carcinogenesis. Nagoya J Med Sci 71: 1-10, 2009.

102. Yamaguchi K, Mandai M, Toyokuni S, Hamanishi J, Higuchi T, Takakura $\mathrm{K}$ and Fujii S: Contents of endometriotic cysts, especially the high concentration of free iron, are a possible cause of carcinogenesis in the cysts through the iron-induced persistent oxidative stress. Clin Cancer Res 14: 32-40, 2008.

103. Sandhu JK, Haggani AS and Birnboim HC: Effect of dietary E on spontaneous or nitric oxide donor-induced mutations in a mouse tumor model. J Natl Cancer Inst 92: 1429-1433, 2000.

104. Garcia-Alonso FJ, Guidarelli A and Periago MJ: Phenolic-rich juice prevents DNA single-strand breakage and cytotoxicity caused by tert-butylhydroperoxide in U937 cells: the role of iron chelation. J Nutr Biochem 18: 457-466, 2007.

105. Samuni AM, Krishna MC, DeGraff W, Russo A, Planalp RP, Brechbiel MW and Mitchell JB: Mechanisms underlying the cytotoxic effects of Tachpyr - a novel metal chelator. Biochim Biophys Acta 1571: 211-218, 2002.

106. Abalea V, Cillard J, Dubos MP, Sergent O, Cillard P and Morel I: Repair of iron-induced DNA oxidation by the flavonoid myricetin in primary rat hepatocyte cultures. Free Radic Biol Med 26: 1457-1466, 1999. 